\title{
BILANGAN RAMSEY MULTIPARTIT UKURAN UNTUK GRAF POHON DAN GRAF LINTASAN
}

\section{TREE-PATH SIZE MULTIPARTITE RAMSEY NUMBERS}

\author{
Yerti Syahraini Putri*, Effendi, dan Syafrizal Sy \\ Jurusan Matematika, Fakultas Matematika dan Ilmu Pengetahuan Alam \\ Universitas Andalas, Kampus Unand Limau Manis, Padang - Indonesia, 25163 \\ *yertisyahraini06@gmail.com
}

\section{ABSTRACT}

Let $j, l, n, s$ and $t$ be natural number with $n, s \geq 2$ and $j, l, t \geq 1$ then the size multipartite Ramsey number $m_{j}\left(K_{n \times l}, K_{s \times t}\right)$ is defined as the smallest natural number $\xi$ such that an arbitrary coloring of the edges of $K_{j \times \xi}$ using the two colors red and blue, necessarily forces a red $K_{n \times l}$ or a blue $K_{s \times t}$ as subgraph. Let $G$ and $H$ be any graphs, for integer $j \geq 2$ the size multipartite Ramsey number $m_{j}(G, H)=\xi$ is the smallest integer such that every factorization of graph $K_{j \times \xi}:=F_{1} \oplus F_{2}$ satisfies the following candition: either $F_{1}$ contains $G$ as a subgraph or $F_{2}$ contains $H$ as a subgraph. In this paper we obtain the exact values of the size multipartite Ramsey number $m_{j}\left(T_{n}, P_{3}\right)$ for $j \geq 3$. The results show that the size multipartite Ramsey number for tree and path, for integer $n$ and $j \geq 3$, is $m_{3}\left(T_{n}, P_{3}\right)=\left\lceil\frac{n}{3}\right\rceil, m_{4}\left(T_{n}, P_{3}\right)=\left\lceil\frac{n}{4}\right\rceil$, and $m_{3}\left(T_{j}, P_{3}\right)=\left\lceil\frac{n}{j}\right\rceil$.

Keywords : Ramsey, multipartite, size, tree, path

\begin{abstract}
ABSTRAK
Misalkan $j, l, n, s$ dan $t$ adalah bilangan-bilangan asli dengan $n, s \geq 2$ dan $j, l, t \geq 1$ maka bilangan Ramsey multipartit ukuran $m_{j}\left(K_{n \times l}, K_{s \times t}\right)$ adalah bilangan asli terkecil $\xi$ sedemikian sehingga sebarang pewarnaan dari semua sisi $K_{j \times \xi}$ menggunakan dua warna merah dan biru, akan selalu berlaku bahwa $K_{j \times \xi}$ memuat $K_{n \times l}$ merah atau $K_{s \times t}$ biru sebagai subgraf. Untuk sebarang graf $G$ dan $H, j \geq 2$ adalah bilangan bulat, bilangan Ramsey multipartit ukuran $m_{j}(G, H)$ adalah bilangan asli terkecil $\xi$ sedemikian sehingga setiap faktorisasi dari graf $K_{j \times \xi}:=F_{1} \oplus F_{2}$ memenuhi kondisi berikut: $F_{1}$ memuat subgraf $G$ atau $F_{2}$ memuat subgraf $H$. Dalam makalah ini, akan ditentukan nilainilai dari bilangan Ramsey multipartit ukuran $m_{j}\left(T_{n}, P_{3}\right)$ untuk $j \geq 3$. Hasil pada penelitian ini menunjukkan bahwa bilangan Ramsey multipartit ukuran untuk graf pohon dan graf lintasan, untuk sebarang bilangan bulat positif $n$ dan $j \geq 3$, yaitu $m_{3}\left(T_{n}, P_{3}\right)=\left\lceil\frac{n}{3}\right\rceil, m_{4}\left(T_{n}, P_{3}\right)=\left\lceil\frac{n}{4}\right\rceil$, dan $m_{3}\left(T_{j}, P_{3}\right)=\left\lceil\frac{n}{j}\right\rceil$.
\end{abstract}

Kata kunci : Ramsey, multipartit, ukuran, pohon, lintasan.

\section{PENDAHULUAN}

Penentuan bilangan Ramsey merupakan salah satu topik kajian matematika dalam bidang kombinatorika. Perkembangan bilangan Ramsey diawali dari bilangan Ramsey klasik yaitu untuk setiap bilangan bulat positif $m$ dan $n$ bilangan Ramsey $r(m, n)$ adalah bilangan bulat positif terkecil $r$ sedemikian sehingga setiap pewarnaan 
merah-biru pada semua sisi pada graf lengkap $K_{r}$ akan selalu menghasilkan graf lengkap $K_{m}$ merah atau $K_{n}$ biru sebagai subgraf.

Penentuan bilangan Ramsey klasik $r(m, n)=r\left(K_{m}, K_{n}\right)$ dengan $K_{m}$ dan $K_{n}$ adalah graf lengkap dengan $m$ dan $n$ titik adalah suatu masalah yang sulit hingga kini. Karena sampai saat ini hanya sembilan bilangan Ramsey klasik yang baru diketahui. Karena sulitnya mendapatkan bilangan Ramsey klasik untuk nilai $m$ dan $n$ yang lain, maka kajian bilangan Ramsey diperluas untuk sebarang graf yang tak harus lengkap. Bilangan Ramsey untuk sebarang graf ini dinamakan bilangan Ramsey graf.

Salah satu bentuk perluasan konsep dari bilangan Ramsey graf adalah bilangan Ramsey multipartit ukuran. Burger dan Vuuren (2004) memberikan konsep tentang bilangan Ramsey multipartit ukuran sebagai berikut. Misalkan $j, l, n, s$ dan $t$ adalah bilangan-bilangan asli dengan $n, s \geq 2$ dan $j, l, t \geq 1$ maka bilangan Ramsey multipartit ukuran $m_{j}\left(K_{n \times l}, K_{s \times t}\right)$ adalah bilangan asli terkecil $\xi$ sedemikian sehingga sebarang pewarnaan dari sisi $K_{j \times \xi}$ menggunakan dua warna merah dan biru, akan selalu berlaku bahwa $K_{j \times \xi}$ memuat $K_{n \times l}$ merah atau $K_{s \times t}$ biru sebagai subgraf.

Sampai saat ini, beberapa nilai bilangan Ramsey multipartit ukuran untuk kombinasi beberapa graf telah diperoleh, diantaranya bilangan Ramsey multipartit ukuran $m_{j}\left(P_{s}, G\right)$ untuk $j \geq 3$ dan $2 \leq s \leq 3$ dengan $G=W_{n}, S_{n}$ atau $F_{n}$ untuk $n \geq 6$ dikaji oleh Syafrizal Sy, dkk (2007), $m_{j}\left(P_{s}, C_{n}\right)$ untuk $j \geq 3, n \geq 2$ dan $s \geq 3$ atau 4 dikaji oleh Syafrizal Sy (2010). Selanjutnya bilangan Ramsey multipartit ukuran untuk lintasan yaitu $m_{j}\left(P_{s}, P_{t}\right)$ untuk $s=2,3$ dan $t \geq 2$ dikaji oleh Syafrizal Sy, dkk (2005), serta bilangan Ramsey multipartit ukuran $m_{j}\left(P_{3}, B_{n}\right)$ untuk $j \geq 3$ dan $n \geq 1, \mathrm{C}$. Jayawardene dan Jayampathy R mengkajinya pada tahun 2016, dan bilangan Ramsey multipartit ukuran $m_{j}\left(P_{3}, K_{2, n}\right)$ untuk $j \geq 3$ dan $n \geq 1$ pada tahun 2019 dikaji oleh C. J. Jayawardene.

Diberikan dua graf $G_{1}$ dan $G_{2}$, dan bilangan bulat $j \geq 2$, bilangan Ramsey $m_{j}\left(G_{1}, G_{2}\right)$ adalah bilangan asli terkecil $t$ sedemikian sehingga setiap faktorisasi dari graf $K_{j \times t}=F_{1} \oplus F_{2}$ akan memenuhi kondisi berikut: $F_{1}$ memuat $G_{1}$ sebagai subgraf atau $F_{2}$ memuat $G_{2}$ sebagai subgraf (syafrizal Sy, 2020). Bilangan Ramsey multipartit ukuran $m_{j}(G, H)$ untuk $G=T_{n}$ dan $H=P_{n}$ yaitu bilangan Ramsey multipartit ukuran untuk graf pohon dan graf lintasan masih menarik untuk dikaji. Graf pohon yaitu graf 
terhubung dan tidak memiliki siklus. Graf pohon dengan $n$ titik dilambangkan dengan $T_{n}$. Sedangkan graf lintasan dinotasikan dengan $P_{n}$ adalah graf terhubung yang membentuk lintasan yang terdiri dari $n$ titik dan $n-1$ sisi dengan $n \geq 2$.

\section{METODOLOGI}

Untuk menunjukan bilangan Ramsey multipartit ukuran $m_{j}\left(T_{n}, P_{3}\right)=t$ dapat dilakukan dalam dua tahap sebagai berikut:

1) Batas bawah, yaitu menunujukkan bahwa $m_{j}\left(T_{n}, P_{3}\right) \geq t$, dengan cara menunjukkan bahwa terdapat pewarnaan merah-biru pada semua sisi dari graf $K_{j \times t-1}$ yang tidak memuat graf $T_{n}$ merah dan juga tidak memuat graf $P_{3}$ biru.

2) Batas atas, yaitu dengan menunjukkan bahwa $m_{j}\left(T_{n}, P_{3}\right) \leq t$, dengan cara menunjukkan untuk sebarang pewarnaan merah-biru pada semua sisi graf $K_{j \times t}$ memuat graf $T_{n}$ merah atau graf $P_{3}$ biru.

\section{PEMBAHASAN}

Berikut ini disajikan beberapa teorema dari bilangan Ramsey multipartit ukuran untuk graf pohon dan graf lintasan.

Teorema 1. Untuk bilangan bulat $n$, berlaku $m_{3}\left(T_{n}, P_{3}\right)=\left[\frac{n}{3}\right\rceil$.

Bukti. Pertama akan ditunjukkan $m_{3}\left(T_{n}, P_{3}\right) \geq\left\lceil\frac{n}{3}\right\rceil$, dengan cara menunjukkan terdapat pewarnaan merah-biru terhadap semua sisi graf $K_{3 \times\left(\left|\frac{n}{3}\right|-1\right)}$ yang tidak memuat $T_{n}$ merah dan juga tidak memuat $P_{3}$ biru. Perhatikan graf $G=K_{3 \times\left(\frac{n}{3} \mid-1\right)}$, jika semua sisi dari $G$ diberi warna merah maka $G$ tidak memuat $P_{3}$ biru, karena $\frac{n}{3} \leq$ $\left\lceil\frac{n}{3}\right\rceil<\frac{n}{3}+1$ maka $3 \times\left(\left\lceil\frac{n}{3}\right\rceil-1\right)<3 \times\left(\frac{n}{3}+1-1\right)$ karena $3 \times \frac{n}{3}=n$ maka $3 \times$ $\left(\left[\frac{n}{3}\right]-1\right)<n$, sehingga $\left|V\left(K_{3 \times\left(\left[\frac{n}{3}\right]-1\right)}\right)\right|<n$, maka jelas bahwa $G$ juga tidak memuat $T_{n}$ merah.

Selanjutnya, akan ditunjukkan bahwa $m_{3}\left(T_{n}, P_{3}\right) \leq\left\lceil\frac{n}{3}\right\rceil$. Misalkan $t=\left\lceil\frac{n}{3}\right\rceil$, perhatikan graf $F=K_{3 \times t}$, misalkan $F_{1} \oplus F_{2}$ adalah sebarang faktorisasi dari $F$, sedemikian sehingga $F_{1}$ tidak memuat $P_{3}$ maka akan ditunjukkan $F_{2}$ memuat $T_{n}$. Tanpa mengurangi perumuman, karena $F_{1}$ tidak memuat $P_{3}$ maka maksimum 
$F_{1}$ suatu matching. Misalkan $V_{1}=\left\{a_{1}, a_{2}, \ldots, a_{t}\right\}, V_{2}=\left\{b_{1}, b_{2}, \ldots, b_{t}\right\}$ dan $V_{3}=$ $\left\{c_{1}, c_{2}, \ldots, c_{t}\right\}$ adalah himpunan-himpunan partit dari $F$.

\section{Kasus 1. $t$ genap.}

Karena $t$ genap, maka $3 t$ genap, akibatnya $F_{1}$ memuat matching sempurna (lihat Gambar 2.1). Selanjutnya untuk menunjukkan $F_{2}$ memuat $T_{n}$ (lihat Gambar 2.2), oleh karena itu, $m_{3}\left(T_{n}, P_{3}\right) \leq\left\lceil\frac{n}{3}\right\rceil$.

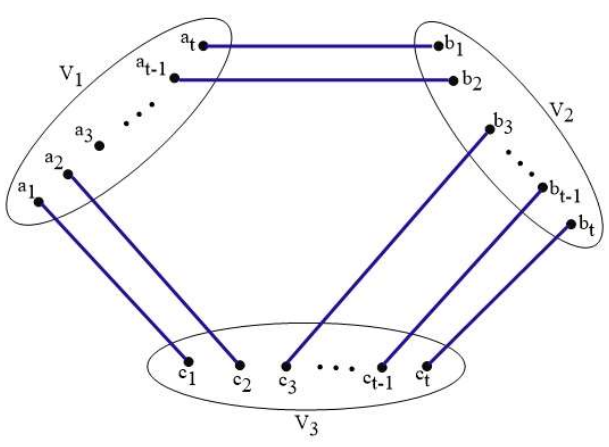

Gambar 2.1. $F_{1}$ tidak memuat $P_{3}$

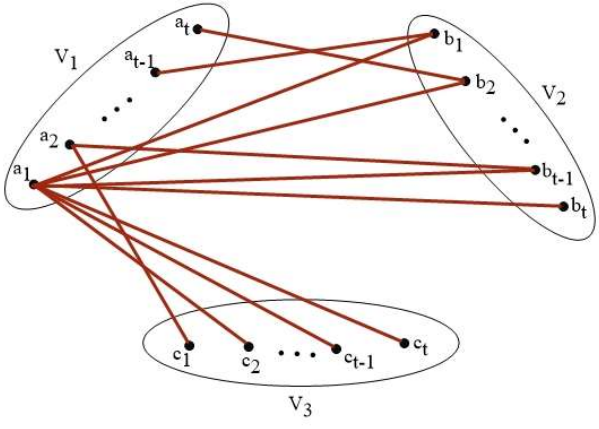

Gambar 2.2. $F_{2}$ memuat $T_{n}$

Kasus 2. $t$ ganjil.

Karena $t$ ganjil, maka $3 t$ ganjil, akibatnya $F_{1}$ memuat matching tidak sempurna (lihat Gambar 2.3). Selanjutnya untuk menunjukkan $F_{2}$ memuat $T_{n}$ (lihat Gambar 2.4), oleh karena itu, $m_{3}\left(T_{n}, P_{3}\right) \leq\left\lceil\frac{n}{3}\right\rceil$.



Gambar 2.3. $F_{1}$ tidak memuat $P_{3}$

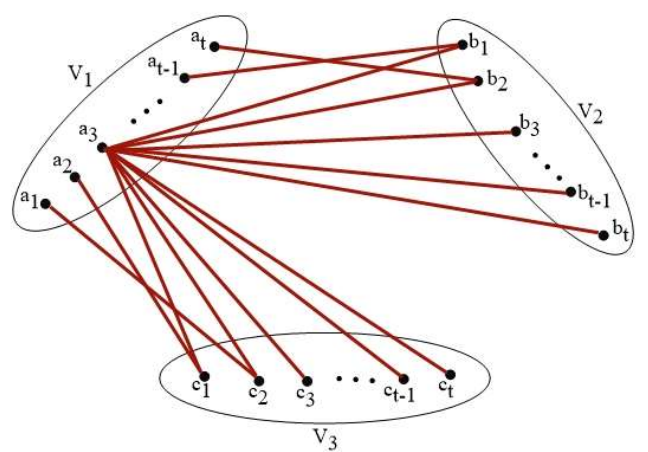

Gambar 2.4. $F_{2}$ memuat $T_{n}$

Teorema 2. Untuk bilangan bulat $n$, berlaku $m_{4}\left(T_{n}, P_{3}\right)=\left\lceil\frac{n}{4}\right\rceil$. 
Bukti. Pertama akan ditunjukkan $m_{4}\left(T_{n}, P_{3}\right) \geq\left\lceil\frac{n}{4}\right\rceil$, dengan cara menunjukkan terdapat pewarnaan merah-biru terhadap semua sisi graf $K_{4 \times\left(\left[\frac{n}{4}\right]-1\right)}$ yang tidak memuat $T_{n}$ merah dan juga tidak memuat $P_{3}$ biru. Perhatikan graf $G=K_{4 \times\left(\left[\frac{n}{4}\right]-1\right)}$, jika semua sisi dari $G$ diberi warna merah maka $G$ tidak memuat $P_{3}$ biru, karena $\frac{n}{4} \leq$ $\left\lceil\frac{n}{4}\right\rceil<\frac{n}{4}+1$ maka $4 \times\left(\left\lceil\frac{n}{4}\right\rceil-1\right)<4 \times\left(\frac{n}{4}+1-1\right)$ karena $4 \times \frac{n}{4}=n$ maka $4 \times$ $\left.\left(\mid \frac{n}{4}\right]-1\right)<n$, sehingga $\left|V\left(K_{4 \times\left(\left[\frac{n}{4}\right]-1\right)}\right)\right|<n$, maka jelas bahwa $G$ juga tidak memuat $T_{n}$ merah.

Selanjutnya, akan ditunjukkan bahwa $m_{4}\left(T_{n}, P_{3}\right) \leq\left\lceil\frac{n}{4}\right\rceil$. Misalkan $t=\left\lceil\frac{n}{4}\right\rceil$, perhatikan graf $F=K_{4 \times t}$, misalkan $F_{1} \oplus F_{2}$ adalah sebarang faktorisasi dari $F$, sedemikian sehingga $F_{1}$ tidak memuat $P_{3}$ maka akan ditunjukkan $F_{2}$ memuat $T_{n}$. Tanpa mengurangi perumuman, karena $F_{1}$ tidak memuat $P_{3}$ maka maksimum $F_{1}$ suatu matching. Misalkan $V_{1}=\left\{a_{1}, a_{2}, \ldots, a_{t}\right\}, \quad V_{2}=\left\{b_{1}, b_{2}, \ldots, b_{t}\right\}, \quad V_{3}=$ $\left\{c_{1}, c_{2}, \ldots, c_{t}\right\}$ dan $V_{4}=\left\{d_{1}, d_{2}, \ldots, d_{t}\right\}$ adalah himpunan-himpunan partit dari $F$. Karena $j$ genap akibatnya $F_{1}$ memuat matching sempurna (lihat Gambar 2.5). Selanjutnya untuk menunjukkan $F_{2}$ memuat $T_{n}$ (lihat Gambar 2.6), oleh karena itu, $m_{4}\left(T_{n}, P_{3}\right) \leq\left\lceil\frac{n}{4}\right\rceil$.

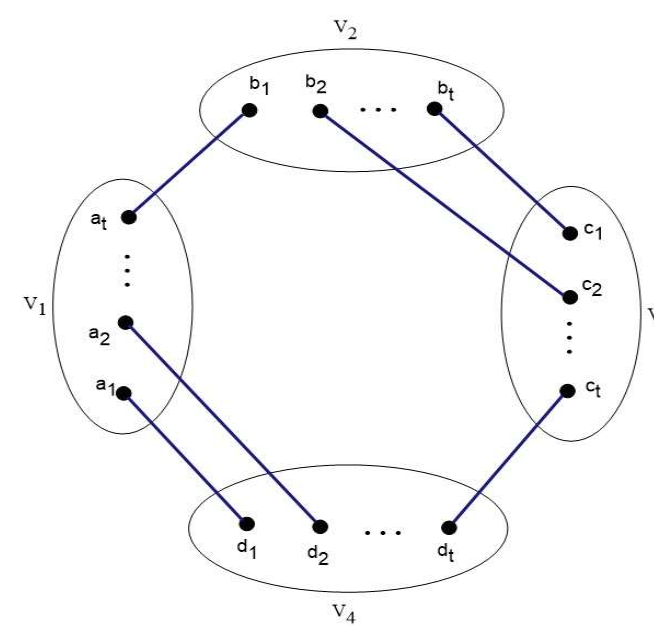

Gambar 2.5. $F_{1}$ tidak memuat $P_{3}$

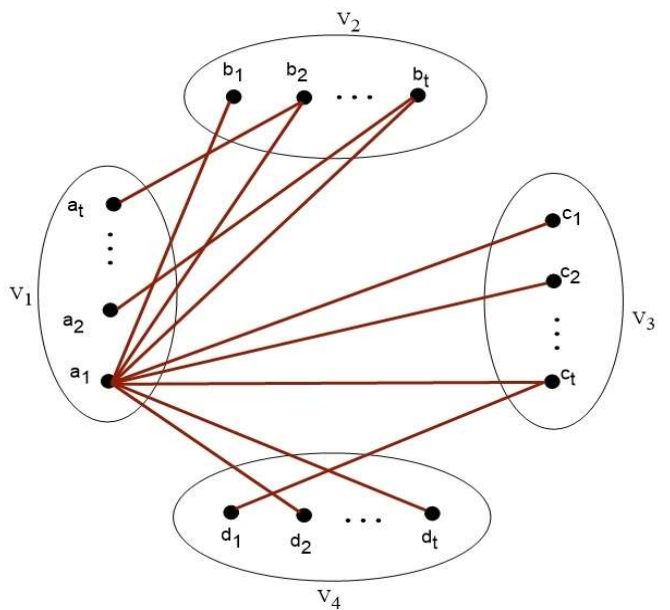

Gambar 2.6. $F_{2}$ memuat $T_{n}$ 
Berikut diberikan teorema tentang bilangan Ramsey multipartit ukuran untuk graf pohon dan $P_{3}$ dalam bentuk umum, yaitu untuk sebarang bilangan bulat positif $n$ dan $j \geq 3$.

Teorema 3. Untuk sebarang bilangan bulat positif $n$ dan $j \geq 3$, berlaku $m_{j}\left(T_{n}, P_{3}\right)=\left\lceil\frac{n}{j}\right\rceil$.

Bukti. Pertama akan ditunjukkan $m_{j}\left(T_{n}, P_{3}\right) \geq\left\lceil\frac{n}{j}\right\rceil$, dengan cara menunjukkan terdapat pewarnaan merah-biru terhadap semua sisi graf $K_{j \times\left(\left[\frac{n}{j}\right]-1\right)}$ yang tidak memuat $T_{n}$ merah dan juga tidak memuat $P_{3}$ biru. Perhatikan graf $G=K_{j \times\left(\left\lceil\frac{n}{j}\right]-1\right)}$, jika semua sisi dari $G$ diberi warna merah maka $G$ tidak memuat $P_{3}$ biru, karena $\frac{n}{j} \leq$ $\left\lceil\frac{n}{j}\right\rceil<\frac{n}{j}+1$ maka $3 \times\left(\left\lceil\frac{n}{j}\right\rceil-1\right)<j \times\left(\frac{n}{j}+1-1\right)$ karena $j \times \frac{n}{j}=n$ maka $j \times$ $\left(\left[\frac{n}{j}\right]-1\right)<n$, sehingga $\left|V\left(K_{\left.j \times\left(\mid \frac{n}{j}\right]-1\right)}\right)\right|<n$, maka jelas bahwa $G$ juga tidak memuat $T_{n}$ merah.

Selanjutnya, akan ditunjukkan bahwa $m_{j}\left(T_{n}, P_{3}\right) \leq\left\lceil\frac{n}{j}\right\rceil$. Misalkan $t=\left\lceil\frac{n}{j}\right\rceil$, perhatikan graf $F \cong K_{j \times\left[\frac{n}{j}\right]}$, dan semua sisi dari $F$ diberi warna merah-biru secara sebarang sedemikian sehingga $F$ tidak memuat $P_{3}$ biru, maka akan ditunjukkan $F$ memuat $T_{n}$ merah.

Sekarang, misalkan $V_{1}, V_{2}, \ldots, V_{j}$ adalah himpunan-himpunan partit dari $F$. Selanjutnya karena $F$ tidak memuat $P_{3}$ biru, maka maksimum $F$ memuat suatu matching, dan setiap sisi pada matching tersebut diberi warna biru, maka jelas bahwa $F$ tidak memuat $P_{3}$ biru. Untuk menunjukkan bahwa $F$ memuat $T_{n}$ merah. Misalkan $F_{1} \oplus F_{2}$ adalah sebarang faktorisasi dari $F$. Perhatikan dua kasus berikut.

Kasus 1. $j$ ganjil.

Dari Teorema 1, dapat dilihat bahwa:

Subkasus 1.1. Jika $t$ ganjil.

Karena $t$ ganjil, maka $j t$ ganjil, sehingga $F$ memuat matching tidak sempurna dalam $F_{1}$, dengan menghubungkan titik-titik di $V_{1}, V_{2}, \ldots, V_{j}$ maka diperoleh sisi-sisi yang membentuk $T_{n}$ dalam $F_{2}$ dengan $n=(j-1) t+1+t-1=j t$, karena $j t=j\left\lceil\frac{n}{j}\right\rceil=$ 
$n$ maka jelas bahwa $F_{2}$ memuat $T_{n}$ sebanyak $n$ titik. Oleh karena itu, $m_{j}\left(T_{n}, P_{3}\right) \leq$ $\left\lceil\frac{n}{j}\right\rceil$.

Subkasus 1.2. Jika $t$ genap.

Karena $t$ genap, maka $j t$ genap, sehingga $F$ memuat matching sempurna dalam $F_{1}$, dengan menghubungkan titik-titik $V_{1}, V_{2}, \ldots, V_{j}$ maka diperoleh sisi-sisi yang membentuk $T_{n}$ dalam $F_{2}$ dengan $n=(j-1) t+t-1+1=j t$, karena $j t=j\left\lceil\frac{n}{j}\right\rceil=n$, maka jelas bahwa $F_{2}$ memuat $T_{n}$ sebanyak $n$ titik. Oleh karena itu, $m_{j}\left(T_{n}, P_{3}\right) \leq\left\lceil\frac{n}{j}\right\rceil$.

Kasus 2. $j$ genap.

Dari Teorema 2 pada $F_{2}$ dipunyai $T_{n}$ sebanyak $n$ titik, yaitu dengan menghubungkan titik-titik di $V_{1}, V_{2}, \ldots, V_{j}$ maka diperoleh sisi-sisi yang membentuk $T_{n}$ dengan $n=(j-1) t+t-1+1=j t$ karena $j t=j\left\lceil\frac{n}{j}\right\rceil=n$, maka jelas bahwa $F_{2}$ memuat $T_{n}$. Oleh karena itu, $m_{j}\left(T_{n}, P_{3}\right) \leq\left\lceil\frac{n}{j}\right\rceil$.

\section{SIMPULAN}

Pada makalah ini, dilakukan kajian yang berkaitan dengan masalah penentuan bilangan Ramsey multipartit ukuran untuk kombinasi graf pohon dan graf lintasan $P_{3}$ untuk sebarang bilangan bulat positif $n$ dan $j \geq 3$, yaitu $m_{j}\left(T_{n}, P_{3}\right)$. Berikut ini adalah hasil-hasil yang telah diperoleh.

1) Untuk bilangan bulat positif $n$, berlaku $m_{3}\left(T_{n}, P_{3}\right)=\left\lceil\frac{n}{3}\right\rceil$.

2) Untuk bilangan bulat positif $n$, berlaku $m_{4}\left(T_{n}, P_{3}\right)=\left\lceil\frac{n}{4}\right\rceil$.

3) Untuk sebarang bilangan bulat positif $n$ dan $j \geq 3$, berlaku $m_{j}\left(T_{n}, P_{3}\right)=\left\lceil\frac{n}{j}\right\rceil$.

\section{DAFTAR PUSTAKA}

Alewyn P. Burger., \& J. H Van Vuuren. 2004. Ramsey Number In Complete Balance Multipartite Graphs, Part II : Size Numbers, Discrete Math, 283, 45-49.

Chula Jayawardene., \& Jayampathy R. 2016. Size Multipartite Ramsey Numbers For Small Paths Versus Books, Indonesia Journal of Combinatorics, 31-40. 
C. J. Jayawardene. 2019. Size Multipartite Ramsey Numbers For Small Paths vs $K_{2, n}$. Annals of Pure and Applied Mathematics, 19(1), 7-17.

Syafrizal Sy., Baskoro E.T., \& Uttunggadewa S. 2005. The Size Multipartite Ramsey Numbers For Paths. J. Combin. Math, Comput, 55, 103-107.

Syafrizal Sy., Baskoro E.T., \& Uttunggadewa S. 2007. The Size Multipartite Ramsey Numbers For Small Paths Versus Other Graphs. Far East J. Appl. Math, 28(1), 131-138.

Syafrizal Sy \& Effendi. 2020. The Size Multipartite Ramsey Numbers $m_{j}\left(P_{n}, K_{j \times b}\right)$. Ins. J. Appl. Math, 33(2), 305-311

Syafrizal Sy. 2010. On Size Multipartite Ramsey Numbers For Paths Versus Cycles Of Three Or Four Vertices. Far East J. Appl. Math, 28(pp), 109-116. 